\title{
Study on the Issue of Supply-Side Reform Path in China's Marine Ecological Civilization Construction
}

\author{
Yang Liu, Zhaobin Pei, Yue Wang \\ Dalian Ocean University, Dalian, Liaoning, China
}

\begin{abstract}
The construction of marine ecological civilization is the cornerstone of China's marine ecological civilization and it is of great strategic significance. This paper analyzes the existing problems in the construction of marine ecological civilization from the angle of economics and the essence of the problem is the imbalance between supply and demand. It is imperative to strengthen supply management. On this foundation, it is concluded that the marine ecological civilization needs supply-side structural reform and it puts forward to optimize the industrial structure, develop high-end distinctive industrial clusters, and promote the industrial transfer. According to the principal-agent theory, the Marine Ecological Civilization Governance Committee is set up to improve the marine ecological civilization supply system. Insist on protecting environment and saving resources, and implement a strict legal system and accountability mechanisms. The implementation of marine ecological environment sharing and co-construction and the establishment of cooperative platform are the paths to promote supply-side reform of the marine ecological civilization construction.
\end{abstract}

Keywords: marine ecological civilization, supply-side reform, efficient

The construction of marine ecological civilization plays an important role in the strategy of ocean power, and is closely related to the development of social economy. Strengthening the construction of marine ecological civilization is an inevitable choice to promote high quality and efficient development of the social economy and meet the people's needs for a better life. Since the 18th National Congress of the Communist Party of China, the party, and the state have attached great importance to marine ecological civilization and actively promoted the building of marine ecological civilization, given priority to marine ecological and environmental protection, and made a series of top-level designs and arrangements in theory, planning, system, and supervision. The report of the 19th National Congress of the Communist Party of China also clearly stated that "the modernization we want to build is the modernization of harmonious coexistence between man and nature". It can be seen that the country has never slacked off the construction of the ecological environment. After the unremitting efforts of the state and local governments, China's marine ecological environment has improved significantly. The marine ecological management has achieved initial results. However, with the acceleration of the process of marine development and utilization, the marine ecological problems remain outstanding: The construction of marine ecological civilization is insufficient. The state of continuous deterioration of the marine ecological environment has not been effectively curbed and improved from the root

Yang Liu, Ph.D., associate professor, Law School and Coast Guard School, Dalian Ocean University, Dalian, Liaoning, China. Zhaobin Pei, Ph.D., professor, Law School and Coast Guard School, Dalian Ocean University, Dalian, Liaoning, China. Yue Wang, Master of Laws, Law School and Coast Guard School, Dalian Ocean University, Dalian, Liaoning, China. 
cause. Industrial and civil sewage has spread wildly on China's long coastline; touched the marine ecological protection law red line and the wantonly behaviors of polluting environment have been repeatedly prohibited; greenhouse gas emissions from land and other pollutants cause ocean acidification more serious, and the marine ecological environment is sensitive and fragile; heavy metals are transported and accumulated step by step in the food chain. Therefore, it is imperative to accelerate the supply-side structural reform of marine ecological civilization construction.

\section{Economic Analysis of Marine Ecological Civilization Construction}

The object of marine ecological civilization construction is the whole marine ecosystem, which mainly includes marine resources and marine environment. Marine resources and environment are the basic components of natural ecosystems, which have important supporting functions for other life systems in nature, and are also important material wealth and space resource which provides for human survival and development. In terms of its nature, it has obvious duality: natural attribute and economic attribute.

First, marine resources and the environment have natural attribute. The ocean is a natural geographical unit formed in nature. It is an ecosystem endowed by nature. It is an important material component of nature. It has objective reality and follows the laws of natural operation. Its primary attribute is the natural attribute. The ocean is mainly an open, balanced, and stable natural integrated system composed of marine resources and environment. It has its own prescriptiveness and value, and is a pure material productivity and energy resource. The production process is a process of benign circulation and energy conservation transformation driven by natural external forces and internal forces of the ocean. The processes of decomposition, reconstruction, regeneration, and restoration of physical energy have obvious spontaneity and initiative. The ocean forms its own carrying capacity in terms of quality, quantity, space, and time based on resources and environment. Human beings should conform to the ocean, respect the law of the ocean's own development, and be in harmony with the ocean. Only when people are in harmony with the ocean can they obtain sustainable benefits, and

The natural world should not be treated as an alien or external conquering object. We must always remember that we rule the natural world, and never like the conquerors who rule the aliens, never like people outside the natural world. (Yu, 2002, pp. 22-23)

After all, human beings are part of nature and do not exist independently of nature. We cannot rely on technology to create everything and despise all aid and supply from nature. Otherwise, "she (natural) will retaliate on the extent to the degree of our rashness" (Chen, 1986, pp. 1-8).

Second, marine resources and the environment have economic attributes. Human survival and development are inseparable from the means of production and living space provided by the ocean. The ocean is the material basis for human survival and the prerequisite for social and economic development. Human development and utilization of the ocean is a process of gradual upgrading from low to high. As a result, once human beings develop and utilize the ocean, they will brand the ocean with human will, and the ocean will become a humanized nature and become a realistic field of activity. Marine resources and the environment will have modern economic attributes. Because people are social in their reality, have the needs of survival and development, are rational economic man, and will inevitably divide from social division of labor, market exchange, production cost, consumption demand, development quality, economic benefits, the status in the entire national economy, and other aspects of the analysis of marine resources and the environment. 
The economic attribute of marine resources and the environment are mainly reflected as follows: The first is the commodity attribute. Karl Marx gave a clear explanation of the duality of goods: value and use value. The use value of marine resources and environment is generally recognized, and its value is gradually recognized by the society, which is existed objectively. At this point, marine resources and the environment have the attributes of commodities. The second is externality. Marine resources and the environment have both positive externalities and negative externalities. Their positive externalities are mainly reflected in the utilization of marine resources and environmental protection, which makes social benefits greater than private benefits. Its negative externalities are mainly reflected in the fact that emitters destroy marine resources and the environment, and damage social benefits, but they have gained rich personal interests; protectors have protected marine resources and the environment, and increased social benefits, while individuals have little income. The third is public goods or quasi-public goods. Non-competitive, marine ecological resources and environment under the given supply, the new marginal cost of providing a new consumer to provide marine ecological products is zero; non-exclusive, consumers can not prevent other consumption when using marine resources and the environment for their consumption. The fourth is scarcity. Marine resources and environmental production cycles are long and cannot be repaired even once destroyed. Because marine resources and the environment have economic attributes, we can analyze the benefits and quality of marine ecological civilization construction from the perspective of economics.

\section{New Problems in the Construction of Marine Ecological Civilization}

In the new century, China has gradually strengthened the construction of marine ecological civilization, especially in the aspects of marine environmental protection and governance, marine resource utilization and development, marine spatial layout, marine functional area planning, marine system and management, etc. And now periodic results have been achieved; the marine environment has improved significantly. However, due to the accelerating industrialization and urbanization in China and the increasing demand for oceans, a large number of population, industry, and production factors are rapidly gathering in coastal areas. The energy exchange between land and sea is accelerated, and the ecological pressure of the entire sea area is rapidly increasing. It is suffering from an unprecedented impact, the new changes and new phenomena have emerged in the construction of marine ecological civilization.

First, the marine ecological environment is fragile and there is a shortage of marine resources. The ocean and land are spatially integrated and linked, and land becomes an important source of marine environmental pollution. Greenhouse gases and pollutants emitted by industry, automobiles, and other sources will enter the ocean in the atmospheric circulation and soil erosion, forcing the ocean to accept a large number of pollutants and that has led to the increasing severity of ocean acidification and the increasing scope of marine pollution. The problem of marine environmental pollution is easily transmitted and recycled within the marine ecosystem. The pollution is intertwined and gradually accumulates, causing further pollution of the marine environment. The utilization and layout of modern marine space is moving towards seaside city group, marine industrial parks, marine power stations, maritime airports, maritime shipping, sea-crossing bridges, undersea tunnels, and marine pastures. These projects have seriously damaged the dynamic balance of the original coastal zone, and it has lead to a sub-health or unhealthy state of the marine ecosystem. The increasing amount of sewage discharged by industry and residents and the frequent occurrence of red tides endanger the habitats on which marine life depends, inhibiting the regeneration of marine living resources and the natural purification of 
seawater, leading to the decline of marine biodiversity and a sharp decline of marine life. The amount of marine fisheries has been removed or even disappeared, the marine ecosystem has been damaged, the degradation and loss of marine resources has become increasingly severe, and the marine ecological carrying capacity has continued to decline. Marine ecological disasters have occurred from time to time.

Second, the spatial layout of the marine economy is misplaced and the industrial structure is not reasonable. At present, China has formed a number of sea-related national-level marine industrial parks. However, due to the economic development gap in coastal areas, the driving force of marine science and technology innovation is different, the influence of marine policy support and the difference in pilot roles, the spatial layout of the marine economy is in a differential pattern. It is represented by the spatial pattern of "three districts and one belt". The northern districts are Liaoning, Hebei, Tianjin, and Shandong, the eastern districts are Jiangsu, Shanghai, and Zhejiang, and the southern districts are Fujian, Guangdong, Guangxi, and Hainan; the "one belt" is along the coastline. The characteristics of the marine industry clustering in the northern districts are obvious. The shipbuilding industry, the marine engineering equipment industry, and the marine chemical industry industrial chain are relatively complete, and the overall competitiveness is strong. The eastern region's marine industry has high extroversion, which is the gathering area of China's port industry, shipbuilding industry, and the marine service industry; the southern area started late, the industrial layout showed a non-equilibrium state, the sea-related industrial structure was diversified and decentralized, and the combine effect of the industrial layout was not obvious. It can be seen that the current spatial layout of the marine industry is a separate battle, lacking top-level design and overall planning at the national level. The coordination and synergy of industrial layout and industrial development in each sea area are poor, and the resource sharing mechanisms of various sea areas have not yet been formed. In addition, most of China's marine strategic emerging industries are characterized by low-level redundant construction, the development of marine high-tech emerging industries, such as deep processing of marine products, sea-related port construction projects, deep-sea resource exploration, deep-sea seabed biology, and marine chemical industry is relatively lagging; production factors are concentrated in the low-end industrial chain of the ocean, causing the dislocation of supply and demand in marine industrial structure, over supply of low-end products, and insufficient production capacity of high-end products, unable to meet consumer demand, and demand spillovers are obvious, seriously restricting the health of the marine industry. Those have led to a lack of core competitive advantages in the development of marine economy. China's marine economy has prominent structural problems. It is imperative to adjust from non-equilibrium to a more balanced state and from a passive high-cost equilibrium to a proactive and lower-cost equilibrium. And in the process of adjusting from non-equilibrium to equilibrium, that is, releasing the marine economic potential, inspiring the vitality of the marine economy, synthesizing the new impetus for the development of marine economy, and creating an "upgraded version" of marine economy, it is necessary to play the role of industrial structure adjustment of supply management objectively. That is to say, we should strive to increase effective supply on the short board of marine industrial structure.

Third, the marine ecological compensation regulations are lagging behind. China has not yet issued a special marine ecological compensation law. The existing legal provisions are scattered in the Environmental Protection Law, the Marine Environmental Protection Law and related management regulations and management methods. There is a lack of effective connection, relevance, and operability between relevant laws and local management regulations. Sensitive issues, such as compensation related to marine ecological 
compensation practices are not even stipulated or the regulations are too general and cannot be relied upon, and there are legal blind spots. Even if certain legal provisions for certain marine ecological problems are made, they are obviously lack of foresight and sustainability, especially for the possibility of marine ecological damage and the lack of defensiveness and early warning of pollution. There is a lack of a special marine ecological compensation legal system based on coordination of the rights and responsibilities of the entire ocean sustainable development level. It has caused confusion in the principles of compensation, the compensation pattern, the compensation procedures, and so on. Moreover, the lack of legislation on current marine ecological compensation laws and regulations also affects the practice of marine ecological compensation in marine ecological pollution accidents. Due to the lack of clear definition of the content and scope of marine ecological compensation and the intersection of integrated marine management and industry management, the powers and responsibilities of the relevant sea management departments are unclear, the power list is vague, and the supervision is insufficient. Although the accountability system of the marine ecological compensation management mechanism has been implemented, in the process of accountability, more emphasis is placed on "question", insufficient attention to "responsibility", or lightly "responsibility", and failure to put responsibility back in place. That makes supervision "tough" and makes the credibility of the integrated sea management department reduced.

\section{The Ocean Ecological Civilization Supply-Side Reform Path}

The report of the 19th National Congress of the Communist Party of China pointed out that "constructing ecological civilization is a millennium plan for the sustainable development of the Chinese nation", and the construction of marine ecological civilization is not only the proper meaning of accelerating the construction of a maritime power, but also creating a road to prosperity along the sea, a road to protection, a road of wisdom and innovation, and a road of cooperation and governance, to achieve the core of human harmony and common development. Therefore, in order to promote the efficient development of marine ecological civilization and deeply abolish the worries of marine ecological civilization construction, we must realize the reform of the supply side of marine ecological civilization, to achieve the goal of co-development with people and the ocean that the use of the ocean, to feed the ocean, to enjoy the ocean, to protect the ocean, "be good with the sea, and be company with the sea". The specific path recommendations are as follows:

First of all, comprehensively establish and implement the marine ecological red line system to build a modernization of harmonious coexistence between people and the sea. The report of the 19th National Congress of the Communist Party of China puts forward:

The modernization that we want to build is the modernization of harmonious coexistence between man and nature. It is necessary to create more material wealth and spiritual wealth to meet the people's growing needs for a better life, and to provide more quality ecology products to meet the needs of the people's growing and beautiful ecological environment.

The marine ecological red line system refers to the sustainable development of the health and ecological security of the marine ecological environment. The marine ecological special functional areas, such as important marine ecological functional areas, marine ecologically vulnerable areas and marine ecological sensitive areas are regarded as key protection and control areas. It is designated as a marine ecological red line, and it is subject to strict classification and classification control, and an effective institutional arrangement for compulsory protection. The third plenary session of the 18th CPC Central Committee (2019) put forward: 
We must build a systematic and complete system of ecological civilization, use the system to protect the ecological environment, delineate the red line of ecological protection, and implement a system of paid use of resources and an ecological compensation system.

The Marine Environmental Protection Law adds: "The State delineates the red line of ecological protection in key marine ecological functional areas, ecologically sensitive areas and vulnerable areas, and implements strict protection"; the report of the 19th National Congress pointed out: "Enhance the ecology System protection, complete the ecological protection red line...establish a market-oriented, diversified ecological compensation mechanism"; "Opinions of the State Council of the Central Committee of the Communist Party of China on Accelerating the Construction of Ecological Civilization" and "Opinions of the General Office of the State Council of the Central Office of the Communist Party of China on delineating and strictly adhering the red line of ecological protection", clear requirements have been made for the delineation of the marine ecological red line. So far, the marine ecological red line system has been fully established throughout the country. The 11 provinces (autonomous regions and municipalities) have initially completed the red line delineation and related start-up work. More than one third of the country's managed waters and more than one third of the mainland are included in the control of the marine ecological red line system. How to refine and implement the marine ecological red line system is the key to the follow-up development. All coastal provinces should implement the specific implementation of the basic principles, organizational forms, management and control indicators and measures for the demarcation of marine ecological red lines issued by the State Oceanic Administration. The rules are submitted to the State Oceanic Administration for review and implementation. Through the implementation of the marine ecological red line system, firmly adhere to the basic bottom line of marine ecological security, implement the most stringent marine ecological environmental protection system, form a green development model of the blue economy, then gradually establish a new paradigm of marine ecological environment protection based on the marine ecological red line system. Adhere to the priority of saving marine resources, protecting marine ecological environment, and restoring marine ecological environment, in order to form a spatial pattern planning and marine industrial structure that conserves resources and protects the environment, and modernizes the harmonious coexistence between people and the sea, also the sea with its due calm, harmony, and beauty of the original state.

Secondly, establish and improve the entry and exit mechanism of the marine industry. Innovation is the driving force for leading the sustainable development of the ocean. At present, China's marine industry is still at the low end of the value chain. Most of them are labor-intensive industries. They are highly dependent on marine resources, highly replaceable, and lack competitiveness. This requires vigorous development of high-tech industries under the concept of green, low-carbon, recycling, and sustainable development, and accelerate the incubation, cultivation, upgrading, extension, and expansion of the mid-to-high-end marine industrial chain, and coordinate the promotion of marine characteristic industrial parks, marine high-tech industrial demonstration bases, and science and technology development of the sea industry bases, leading the high-end and ecological development of the marine industry. Increase financial investment in marine emerging industries and major marine science and technology projects provides tax incentives and related support policy to meet the requirements for high-tech marine industry certification. At the same time, accelerate and deepen cooperation with the developed countries involved in the deep-sea in the seabed oceanographic survey, observation equipment, renewable energy, marine food technology, marine drones, unmanned vessels, and other fields strengthening the cooperation and achievements of marine technology standard system docking and 
marine technology transfer (Xinhua News Agency, 2017) supporting sea-related scientific research institutions and high-end enterprises involved in the sea to jointly build overseas marine technology demonstration and promotion bases, in order to improve marine science and technology innovation capabilities jointly and marine science and technology resources interconnection and sharing platform construction capacity.

Third, strengthen marine environmental protection, strictly enforce the rule of law, and improve the accountability mechanism and marine ecological compensation system. China's marine resources and marine environmental protection have many debts. We should strengthen marine ecological protection from many aspects. On the one hand, we must rely on the inherent strength of marine ecosystems to achieve self-repair and reconstruction, and maintain the stability and sustainability of marine ecology. The mode of interference should gradually shift from pollution control to protection and self-restriction, focusing on marine ecological protection and marine spatial planning, and implementing special purposes in specific areas. "Establishing a connection system for prevention and control of pollution between land and sea areas" (Ke, Cao, Zhang, Chen, \& Cheng, 2013, pp. 71-79). The marine ecological environment is jointly built and protected, actively demarcating the marine ecological red line, planning and establishing marine ecological protection areas, establishing demonstration zones for marine ecological civilization construction, establishing special funds for marine ecological protection, strengthening the comprehensive management of marine ecology, and implement scientific marine ecological environment data monitoring, accelerating the development of green, recycling and low-carbon, and promoting the friendly development of marine ecological environment. On the other hand, improve the marine ecological protection law and improve the accountability system, increase the monitoring of marine ecological environment, and monitor the source, process, and results from the whole process. We will resolutely investigate and punish violations of laws and regulations that touch marine ecological high-voltage lines, increase penalties, and increase the cost of violations. China's "Marine Environmental Protection Law" should give more and more perfect accountability and perfection of the accountability system while giving the management and supervision of marine environmental supervision departments at all levels, implement accountability mechanisms for marine ecological pollution owners, upgrade and update this post-mortem monitoring mechanism with disciplinary and early warning effects, clearly stipulates administrative accountability measures for the regulatory authorities, ensures consistency of powers and responsibilities, clearly categorizes, and comprehensively eliminates acts that damage the marine ecological environment. At present, from the international to the domestic, from the country to the local are constantly exploring the marine ecological compensation system, and achieved relatively outstanding achievements, but in the process of dealing with specific marine environmental issues, it also highlights a series of problems. In the course of specific business operations, it was found that the marine ecological compensation system lacked feasible operating rules and technical guidelines, the supporting data was seriously scarce, and lack of strong technical support. Marine ecological compensation fund is difficult to reach, slow to be put in place, low availability rate, and the compensation channel is not sound and many other problems are serious. Therefore, it is a long way to refine and improve the marine ecological compensation mechanism. From the level of legal norms, the marine ecological compensation system should be written into the Marine Environmental Protection Law to clarify its legal status and provide legal basis and legal support for the specific operation of marine ecological compensation in practice.

Finally, build an ecological sharing and co-construction system and build a cooperation platform for marine ecological civilization construction. Marine ecological protection is everyone's responsibility. We all 
use marine resources and environment directly or indirectly. We should protect marine ecology from multiple channels while enjoying ocean gifts, and form a harmonious and unified relationship with the ocean. Use and protect the ocean on a regular basis. The government should protect the marine environment from macro-planning, policy-oriented, and legal norms. Enterprises should reduce pollution and damage to the oceans from the main responsibility. Social residents should establish a sense of marine environmental protection, adhere to the governance and protection of the marine environment, and protect the oceans. The whole society forms a unified protection of the marine environment. At present, the cooperation platform mechanism for marine ecological civilization construction is imperfect; the government should actively build a cooperation platform. First, we need to jointly build an exchange and cooperation mechanism for protecting the marine ecological environment. Second, we should actively establish an international cooperation platform for marine ecological environment. Third, we should carry out marine planning research and application, and provide technical support for the construction of marine ecological civilization. The fourth is to promote cooperation and exchanges with civil society organizations and non-governmental organizations.

\section{Conclusions}

The construction of marine ecological civilization is a long-term and arduous system project. It is of great significance to the strategy of maritime power. It is an inherent requirement for the transformation and upgrading of the marine economic development mode in coastal areas. Its core and foundation are the utilization of marine resources and environmental protection. To promote the efficient construction of marine ecological civilization, we must strengthen supply-side management on the basis of respecting the self-development rules of marine ecology and the carrying capacity of marine ecological environment; promote reforms from structural management, industrial policies, institutional innovation, and resource policies to eliminate ineffective supply; increase effective supply and reduce construction costs; adhere to priority of protection, green development of blue resources; respect the ocean, adapt to the ocean, protect the ocean, and put the construction of marine ecological civilization in the priority position of marine ecological environment protection; strengthen the scientific design of marine ecological civilization construction, earnestly grasp the equilibrium point of population, economy, and marine resources and environment; and promote the balance of marine ecological supply and demand through supply-side structural reform, so that the two can achieve the best fit through benign interaction, and fundamentally we will reverse the deterioration of the marine ecological environment, build an ecological civilization construction system that respects the blue ocean and green development, comprehensively improve the level of marine ecological civilization construction, and enable the people to enjoy beautiful, harmonious, and rich marine resources.

\section{References}

Chen, A. X. (2016). The study of China's steel industry overcapacity problem on the background of the supply side reform. Journal of Industrial Technological \& Economics, 10, 3-7.

Chen, C. W. (1986). The influence of technology on the development of philosophy. Research on Dialectics of Nature, 2, 1-8.

China.org.cn. (2019). Third plenary session of the 18th CPC Central Committee. Retrieved from http://www.china.org.cn/china/ third_plenary_session/node_7193886.htm

Ke, W., Cao, G. Y., Zhang, J. C., Chen, J., \& Cheng C. Z. (2013). Discussion on the safety of marine eco-environment in the bohai economic circle. Journal of the Pacific, 4, 71-79.

Tong, C. F., \& Xia, F. (2017). Problems and solutions in China's marine fishery against the background of the supply-side reform. Journal of Ocean University of China (Social Sciences), 5, 11-14. 
Wu, Y. P., \& Zhang, Y. (2017). Study on path and policy of energy supply-side reform for China. Resource Development \& Market, 8, 31-36.

Xi, J. P. (2017). Secure a decisive victory in building a moderately prosperous society in all respects and strive for the great success of socialism with chinese characteristics for a new era. Retrieved from http://www.xinhuanet.com/english/ download/Xi_Jinping's_report_at_19th_CPC_National_Congress.pdf

Xinhua News Agency. (2017). The "One Belt and One Road" maritime cooperation concept. Xinhuanet. Retrieved from http://news.xinhuanet.com/politics/2017-06/20/c_1121176798.htm

Yu, Q. (2002). Modern classics. China: Shanghai University Press.

Zhang, Z. G., \& Wu, L. (2017). A study on the mechanism of supply-side structural reform for China's paper industry. Transactions of China Pulp and Paper, 3, 23-26. 